\title{
Limb and skeletal muscle blood flow measurements at rest and during exercise in human subjects
}

\author{
Göran Rådegran \\ Copenhagen Muscle Research Centre, Rigshospitalet, Section 7652, Tagensvej 20, Dk-2200 Copenhagen N, Denmark
}

\begin{abstract}
The aim of the present review is to present techniques used for measuring blood flow in human subjects and advice as to when they may be applicable. Since blood flow is required to estimate substrate fluxes, energy turnover and metabolic rate of skeletal muscle, accurate measurements of blood flow are of extreme importance. Several techniques have therefore been developed to enable estimates to be made of the arterial inflow to, venous outflow from, or local blood flow within the muscle. Regional measurements have been performed using electromagnetic flow meters, plethysmography, indicator methods (e.g. thermodilution and indo-cyanine green dye infusion), ultrasound Doppler, and magnetic resonance velocity imaging. Local estimates have been made using ${ }^{133} \mathrm{Xe}$ clearance, microdialysis, near i.r. spectroscopy, positron emission tomography and laser Doppler. In principle, the aim of the study, the type of interventions and the limitations of each technique determine which method may be most appropriate. Ultrasound Doppler and continuous indo-cyanine green dye infusion gives the most accurate limb blood flow measurements at rest. Moreover, the ultrasound Doppler is unique, as it does not demand a steadystate, and because its high temporal resolution allows detection of normal physiological variations as well as continuous measurements during transitional states such as at onset of and in recovery from exercise. During steady-state exercise thermodilution can be used in addition to indo-cyanine green dye infusion and ultrasound Doppler, where the latter is restricted to exercise modes with a fixed vessel position. Magnetic resonance velocity imaging may in addition be used to determine blood flow within deep single vessels. Positron emission tomography seems to be the most promising tool for local skeletal muscle blood-flow measurements in relation to metabolic activity, although the mode and intensity of exercise will be restricted by the apparatus design.
\end{abstract}

Blood flow: Exercise: Muscle metabolism: Hyperaemia

Physical exercise exerts significant stress on human body functions, both with regards to its effect on the cardiovascular system as well as on metabolic processes (Saltin \& Rowell, 1980; Saltin \& Gollnick, 1983; Saltin, 1985). In order to meet the elevated metabolic demands of active muscle, blood flow increases rapidly at the onset of exercise (Rådegran \& Saltin, 1998; Fig. 1), and linearly in relation to work intensity (Fig. 2), to reach a peak level approximately 50-fold higher than that at rest (Andersen \& Saltin, 1985). Moreover, blood flow continuously oscillates at rest, as an effect of the heart beat and blood pressure. During exercise these oscillations are even more pronounced, being also influenced by the intramuscular pressure variations (Fig. 3). However, the mean value for blood flow may still be considered as steady when these oscillations are short and repeated in a regular pattern. Furthermore, the flow needs to be averaged over a sequence of contraction-relaxation cycles, i.e. approximately $10 \mathrm{~s}$, in order to minimize the normal physiological variation depending on the cyclic relationship between the cardiac cycle, pulse pressure and intramuscular pressure (Rådegran, 1997; Rådegran \& Saltin, 1998).

Several techniques have been developed to enable estimates to be made of the arterial inflow to, venous outflow from, or local blood flow within the muscle (Table 1). Regional limb blood-flow measurements have been performed using electromagnetic flow meters (Cronestrand, 1970), plethysmography (Bygdeman \& Pernow, 1978), indicator methods (Jorfeldt \& Wahren, 1971; Andersen \& Saltin, 1985), ultrasound Doppler (Rådegran, 1997) and magnetic resonance velocity imaging (Hundley et al. 1996). Local estimates have been made using ${ }^{133} \mathrm{Xe}$ clearance 


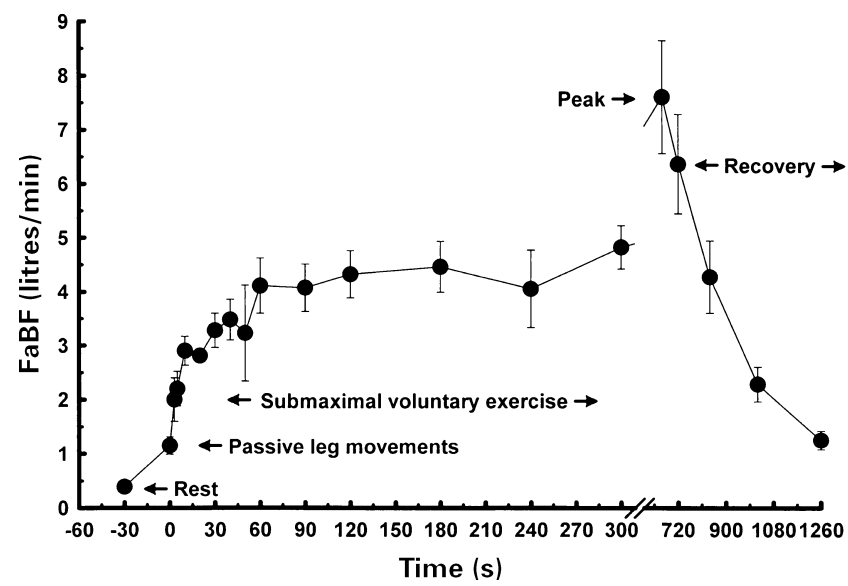

Fig. 1. Femoral artery blood flow (FaBF; ultrasound Doppler) in transition from rest, to passive leg movement, at onset of and during submaximal voluntary knee-extensor exercise, as well as at termination at peak effort, followed by post exercise. Values are means with their standard errors represented by vertical bars for $n 7$ determinations. (From Rådegran \& Saltin, 1999.)

(Lassen et al. 1964), microdialysis (Hickner et al. 1994a; Rådegran et al. 1998), near i.r. spectroscopy (NIRS; Edwards et al. 1993; Boushel et al. 1997), positron emission tomography (PET; Ruotsalainen et al. 1997), and laser Doppler (Jensen et al. 1995). In addition, drop or volume counting, hot-wire anemometer and radioactively-labelled microsphere techniques have been used in animals. An overview will be given of techniques utilized in human subjects, with emphasis on recent methodological refinements which allow the most accurate blood-flow estimates.

\section{Regional blood-flow measurements}

\section{Electromagnetic flow meters}

Principle. The electromagnetic flow meters are based on induction of voltage changes proportional to the flow of blood (Kolin, 1936, 1941; Djordjevich \& Sadove, 1981). As blood is a conductive liquid, an electromotive force is induced, which can be derived as: electromotive force $=\mathrm{B} \times \mathrm{L} \times \mathrm{u}$, where $\mathrm{B}$ is the magnetic flux density $(\mathrm{T}), \mathrm{L}$ is the distance between the electrodes $(\mathrm{m})$, and $\mathrm{u}$ is the instantaneous blood velocity (m/s; Webster, 1978).

Practicalities. The electromagnetic flow probe is intraoperatively mounted directly on the vessel where flow is to be measured (Hall, 1969). Blood flow is calculated from the product of the cross-sectional area of the vessel and the mean flow velocity.

Strength and weaknesses. When the technique was developed it was unique, as instantaneous volumetric pulsatile flow could be calculated. Furthermore, it enabled measurements to be made of blood flow in single vessels at rest and during exercise after reconstruction for occlusive disease (Cronestrand, 1970; Vänttinen, 1975). The equipment is relatively inexpensive and running costs are relatively low. It is, however, too invasive as a standardized method for measuring blood flow in healthy human subjects. Thus, its primary application is restricted to species other than man.

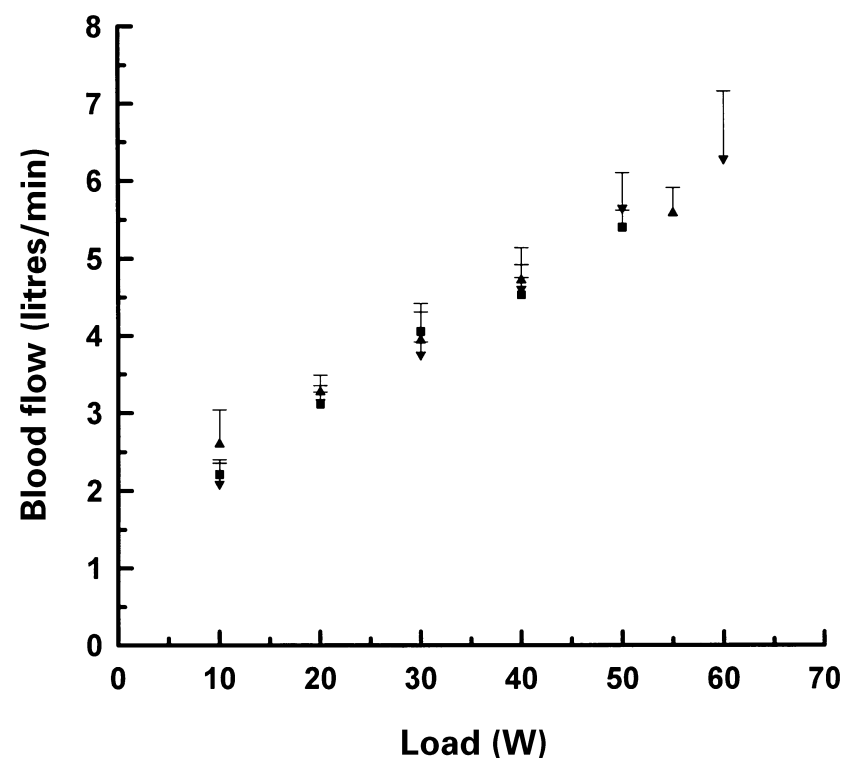

Fig. 2. Linear increase of arterial inflow to, and venous outflow from, the quadriceps muscle during steady-state knee-extensor exercise at incremental intensities. Measurements performed with ultrasound Doppler (averaged in relation to the contraction-relaxation cycles ( $\mathbf{\square}$; $n 10$ determinations) or the electrocardiogram ( $\boldsymbol{\nabla} ; n 5$ determinations); Rådegran, 1997) and thermodilution ( $\boldsymbol{\Delta} ; n 5$ determinations; Andersen \& Saltin, 1985) give similar results. Values are means with their standard errors represented by vertical bars.

\section{Plethysmography}

Principle. Venous occlusion plethysmography is based on determining the volume increase in a limb segment when venous outflow is temporarily arrested but arterial inflow is intact (Bygdeman \& Pernow, 1978). The rate of limb swelling during occlusion is used to assess the rate of arterial inflow. Alternatively, the limb circumference can be used. With no change in the shape of the cross-sectional area with a certain volume increase, the percentage change in area at small changes will be twice the change of the limb circumference (Bygdeman \& Pernow, 1978).

Practicalities. An air-filled plethysmograph was used previously (Bonde-Petersen \& Siggaard-Andersen, 1967, 1969; Siggaard-Andersen \& Bonde-Petersen, 1967; Siggaard-Andersen, 1970). The plethysmograph-manchett and pressure sensor were placed over the widest segment of the limb. A venous and arterial occlusion manchett were placed just proximal and distal to the plethysmographmanchett, and occlusion pressures of approximately 50 and $250 \mathrm{mmHg}$ were applied respectively. However, as increased precision in the circumference measurements was needed, the strain-gauge plethysmograph was developed, which utilizes a strain-gauge sensor placed around the widest part of the limb where flow is to be measured. Knowing the electrical calibration and registering the induced voltage change, the blood flow is calculated based on $\Delta \mathrm{V} / \mathrm{V}=2 \Delta \mathrm{O} / \mathrm{O}=\Delta \mathrm{R} / \mathrm{R}$, where $\mathrm{V}$ is the volume of the limb segment, $\mathrm{O}$ is the circumference, and $\mathrm{R}$ is the electrical resistance of the sensor. At a constant current through the sensor, the voltage will follow the variations in resistance, and the voltage changes will be proportional to the volume 

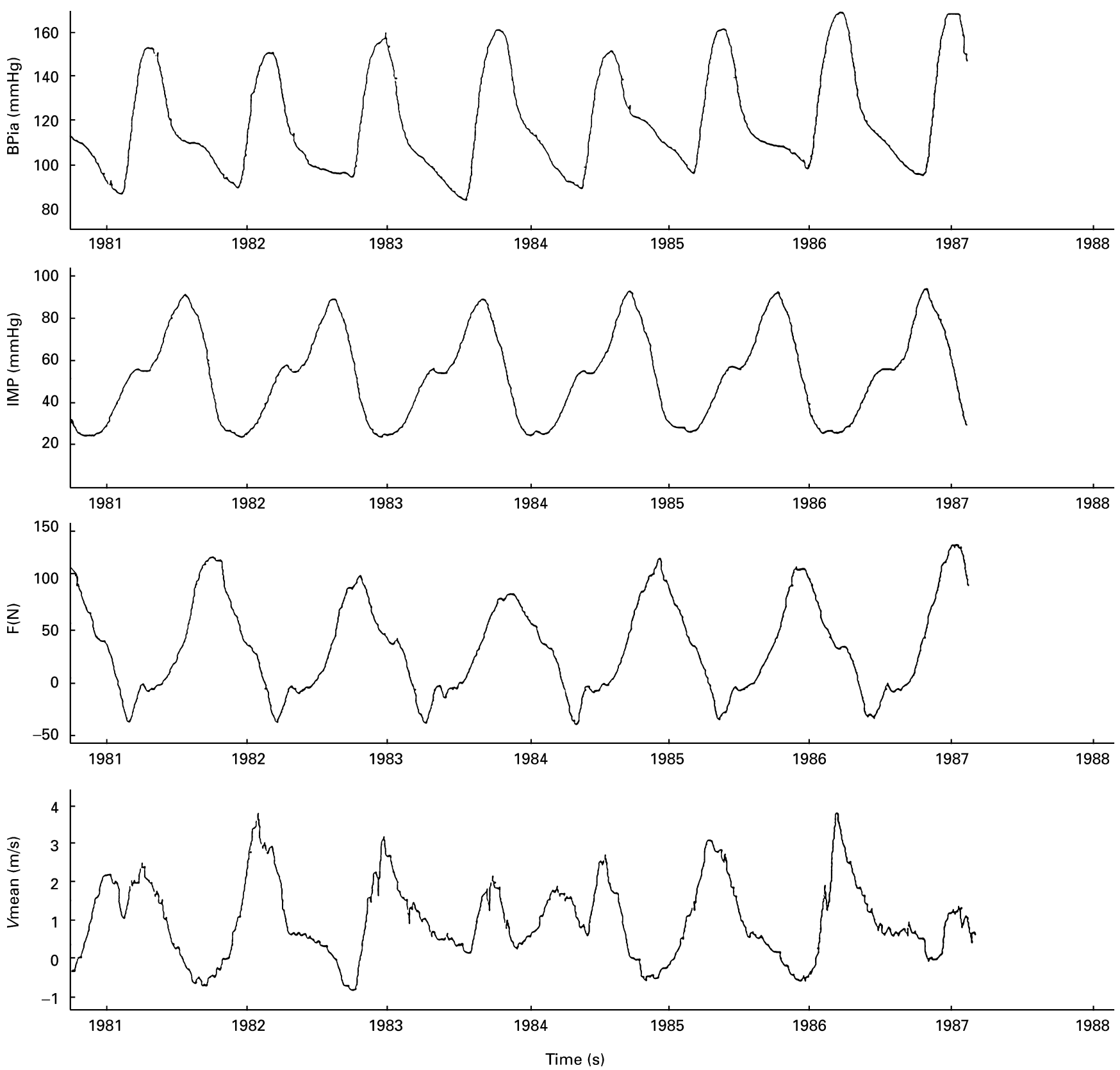

Fig. 3. A continuous tracing of femoral artery blood velocity (Vmean, representing arterial inflow, ultrasound Doppler) during steady-state kneeextensor exercise in relation to the knee-extensor force (F), intramuscular pressure (IMP), and arterial blood pressure (BPia). (From Rådegran \& Saltin, 1998.)

changes of the limb. The blood flow is then calculated from: blood flow $(\mathrm{ml} / \mathrm{min}$ per litre tissue $)=$ deflection size (after $10 \mathrm{~s} ; \mathrm{mm}) \times 6 \times 10 /$ calibration deflection $(\mathrm{mm}$; Bygdeman $\&$ Pernow, 1978).

Strength and weaknesses. The strength of plethysmography is that it is relatively easy to use and noninvasive. Also, the equipment is inexpensive and running costs are low. However, the limitations of the method are clear, as shown by following its technical development (Schäfer \& Moore, 1896; Brodie \& Russell, 1905; Hewlett \& van Zwaluwenburg, 1909; Barcroft \& Dornhorst, 1949; Whitney, 1953; Conrad \& Green, 1961). The original model was cumbersome and required immobilization of the subjects. It was sensitive to movement and induction of local vasomotor changes. Sealing of the limb without inducing tissue constriction was also problematic. Although subsequently the technique was markedly refined, the original fundamental assumptions still have to be fulfilled for plethysmographic flow to equal arterial inflow (Conrad $\&$ Green, 1961). The veins have to be completely occluded, allowing no leakage. The arterial inflow must not be altered initially and the occlusion artifact has to be small. These factors also have to stay constant over the time period of measurement. However, the occlusion pressure has been shown to substantially decrease arterial inflow (Byström et al. 1998). Two intrinsic occlusion errors have also been 
Table 1. Techniques used for regional and local blood flow measurements in human subjects, indicating the type of measurements that may be performed and the relative cost aspects of the techniques

\begin{tabular}{|c|c|c|c|c|}
\hline Blood flow techniques & Comments & Type of measurement & Cost of equipment & Running costs \\
\hline \multicolumn{5}{|l|}{ Regional } \\
\hline Electromagnetic flow meter & $\begin{array}{l}\text { Invasive, probe mounted } \\
\text { on vessel }\end{array}$ & Intra-operative usage & Inexpensive & Inexpensive \\
\hline Plethysmography & Non-invasive, easy to use & Rest & Inexpensive & Inexpensive \\
\hline ICG dye dilution & $\begin{array}{l}\text { Invasive ICG-injection, } \\
\text { blood withdrawal }\end{array}$ & $\begin{array}{l}\text { Rest, submaximal and } \\
\text { maximal exercise }\end{array}$ & Inexpensive & Expensive \\
\hline Thermodilution & $\begin{array}{l}\text { Invasive saline infusion, } \\
\text { easy to use }\end{array}$ & $\begin{array}{l}\text { Rest }^{\star}, \text { submaximal and } \\
\text { maximal exercise }\end{array}$ & Inexpensive & Inexpensive \\
\hline Ultrasound Doppler & $\begin{array}{l}\text { Non-invasive, advanced } \\
\text { to use, continuous } \\
\text { sampling, high temporal } \\
\text { resolution }\end{array}$ & $\begin{array}{l}\text { Rest, transitional changes, } \\
\text { submaximal exercise, } \\
\text { fixed vessel position }\end{array}$ & Expensive & Relatively expensive \\
\hline $\begin{array}{l}\text { Magnetic resonance velocity } \\
\text { imaging }\end{array}$ & $\begin{array}{l}\text { Non-invasive, advanced } \\
\text { to use, continuous } \\
\text { sampling, high temporal } \\
\text { resolution }\end{array}$ & $\begin{array}{l}\text { Rest, light exercise, } \\
\text { restricted by apparatus } \\
\text { design }\end{array}$ & Very expensive & Very expensive \\
\hline \multicolumn{5}{|l|}{ Local } \\
\hline${ }^{133}$ Xe clearance & Invasive ${ }^{133} \mathrm{Xe}$ injection & Non-linear at high intensities & Relatively expensive & Relatively expensive \\
\hline $\begin{array}{l}\text { Microdialysis ethanol outflow: } \\
\text { inflow }\end{array}$ & $\begin{array}{l}\text { Invasive insertion of 'delicate' } \\
\text { microdialysis fibres }\end{array}$ & $\begin{array}{l}\text { Under evaluation, disturbed } \\
\text { by contractions }\end{array}$ & Relatively inexpensive & Relatively expensive \\
\hline Near i.r. spectroscopy-ICG & Invasive ICG injection & Under evaluation & Relatively expensive & Relatively expensive \\
\hline Laser Doppler & $\begin{array}{l}\text { Invasive insertion of optical } \\
\text { fibre }\end{array}$ & Under evaluation & Relatively expensive & Inexpensive \\
\hline Positron emission tomography & $\begin{array}{l}\text { Invasive, injection of } \\
\text { positron emitting isotopes, } \\
\text { advanced to use }\end{array}$ & $\begin{array}{l}\text { Rest, light exercise, } \\
\text { restricted by apparatus } \\
\text { design }\end{array}$ & Very expensive & Very expensive \\
\hline
\end{tabular}

ICG, indo-cyanine green.

* Bolus injections at rest only reflect a short time period.

found to work in opposing directions, leading to a tendency towards inaccuracy (Conrad \& Green, 1961). Furthermore, it is important to note that measurements performed after or in-between contractions only reflect an immediate postexercise value and not exercise per se. Thus, due to its inherent limitations and the motion artifacts induced by exercise, it is limited to intermittent measurements at rest only (Williams \& Lind, 1979; Benjamin et al. 1995).

\section{Indicator methods: overview}

The indicator methods require steady-state conditions which must not be altered by injection of the indicator (Lassen et al. 1983). Different types of indicators have been used such as intravascular indicators (e.g. indo-cyanine green (ICG) dye, Evans-blue, labelled microspheres and labelled albumin), freely-diffusable indicators (e.g. ${ }^{133} \mathrm{Xe}$, heat, $\mathrm{N}_{2} \mathrm{O}$ and $\mathrm{H}_{2}$ gas) that pass through the cell membranes, as well as small hydrophilic extracellular indicators (e.g. sucrose, EDTA and inulin) which distribute in the interstitial space via passage through pores in the capillary walls.

A distinction is made depending on whether the measurements are based on dilution (e.g. thermodilution and dye dilution) or perfusion (e.g. ${ }^{133} \mathrm{Xe}$ clearance) detection procedures. In order for the indicators to be indicative of blood flow they must not be retained or be metabolized. The indicators must also be fully mixed with the blood. Specifically for the dilution method based on heat transfer, a thorough mixing must occur before reaching the nearby sampling point. For dye dilution the 'mixing' and binding to a carrier must occur before it spreads into the capillary network. The perfusion method estimating capillary flow (by external detection of the wash-out of an injected tracer) is addressed under local blood-flow measurements.

\section{Indicator methods: indo-cyanine green dye}

Principle. Dye dilution is based on the assumption that the indicator concentration in blood is flow-dependent (Lassen et al. 1983).

Practicalities. The ICG dye procedure was initially developed to measure cardiac output (Stewart, 1897, 1921), but according to the same principles may be used for limb blood-flow measurements. Blood flow may be measured by infusion of dye of known concentration at a specific rate and site upstream in a vessel, followed by determination of the dye concentration (using a photo-densitometer) in blood samples withdrawn after thorough mixing at a point downstream. Blood flow $=\mathrm{j}_{\text {in, } \infty} / \mathrm{C}_{\text {out }, \infty}$, where $\mathrm{j}_{\text {in, }, \infty}$ represents the steady-state infusion rate $(\mathrm{mg} / \mathrm{min})$ and $\mathrm{C}_{\text {out }, \infty}$ is the steadystate outlet concentration of the dye. This equation is valid if it is assumed that there is no re-circulation, which may give a constant rising dye curve (Lassen et al. 1983). However, correction for re-circulation can be made where there is bilateral symmetry, by subtracting the signal in the outlet of a non-infused limb from that for the limb within which blood flow is to be determined. A prerequisite, however, is that both limbs have the same mean transit time, and thus are at the same state of activity. Re-circulation is further minimized by using intravascular indicators such as ICG 
that quickly reach a steady-state, and indicators that re-circulate minimally, as well as by infusion upstream close to the mixing site and sampling downstream close to this site. With regard to leg blood-flow measurements during intense bicycle exercise, two different approaches have been used: infusing the dye either in the femoral artery or in the distal part of the femoral vein and sampling the blood in the proximal part of the femoral vein at the level of the inguinal ligament, where uniform mixing could be ensured (Jorfeldt \& Wahren, 1971; Wahren \& Jorfeldt, 1973).

Strength and weaknesses. Continuous ICG infusion gives reliable measurements at rest when infused for an extended period of time, i.e. approximately $3 \mathrm{~min}$ (Jorfeldt $\&$ Wahren, 1971). It also gives accurate intermittent steadystate measurements during incremental exercise up to peak effort when infused for approximately $1 \mathrm{~min}$ and $20 \mathrm{~s}$ (Jorfeldt \& Wahren, 1971). Furthermore, it is not restricted to a specific type of exercise mode. However, the technique is invasive, requiring dye infusion. It is also slightly more troublesome to perform than thermodilution as it involves sampling and handling of blood which may have to be re-infused in order to avoid a blood loss. The equipment is relatively inexpensive, but the running expenses of ICG are high.

\section{Indicator methods: thermodilution}

Principle. Thermodilution blood-flow measurements are based on the thermodynamic heat balance relationship (Ganz \& Swan, 1974), knowing the specific heats of blood, the infusion solution and their mixture, as well as the masses of blood and the infusion solution. Blood flow is determined by measuring the temperature change in a vessel during simultaneous infusion of cold saline $(9 \mathrm{~g} \mathrm{NaCl} / \mathrm{l})$. The temperature deflection is proportional to the temperature and rate of saline infusion, as well as the flow rate of blood.

Practicalities. A thermistor and a catheter are inserted into a peripheral vessel in the proximal and either proximal or distal direction respectively. Improved mixing may be achieved by infusing the saline against the bloodstream. The blood flow $(\mathrm{ml} / \mathrm{min})$ is calculated as blood flow $=\left(\mathrm{V}_{\mathrm{I}} \times\left(\mathrm{S}_{\mathrm{I}} \times \mathrm{C}_{\mathrm{I}}\right) /\left(\mathrm{S}_{\mathrm{B}} \times \mathrm{C}_{\mathrm{B}}\right)\right) \times\left(\left(\left(\mathrm{T}_{\mathrm{B}}-\mathrm{T}_{\mathrm{I}}\right) /\left(\mathrm{T}_{\mathrm{B}}-\mathrm{T}_{\mathrm{M}}\right)\right)-1\right)$, after measuring the blood temperature $T_{B}$ before saline infusion, the temperature of the infusate $T_{I}$ during infusion, the temperature of the blood and saline mixture $\mathrm{T}_{\mathrm{M}}$ during the steady-state infusion, and calculating the resulting temperature deflection $\left(\Delta \mathrm{T}=\mathrm{T}_{\mathrm{B}}-\mathrm{T}_{\mathrm{I}}\right) . \mathrm{V}_{\mathrm{I}}$ is the infusion rate $(\mathrm{ml} / \mathrm{min})$ of the infusate, $S_{i}(1.005)$ and $S_{B}(1.045)$ are the specific gravities of the infusate and blood respectively, and $\mathrm{C}_{\mathrm{I}}\left(4.17 \mathrm{~kJ} / \mathrm{g} \mathrm{per}^{\circ}\right)$ and $\mathrm{C}_{\mathrm{B}}\left(3.51 \mathrm{~kJ} / \mathrm{g}\right.$ per $\left.^{\circ}\right)$ are the specific heats of the infusate and blood respectively.

The thermodilution technique, originally developed for cardiac output measurements (Fegler, 1954), was adopted in the early 1960 s for peripheral blood-flow measurements (Fronek \& Ganz, 1960; Ganz et al. 1964). The method has subsequently been refined in a series of studies (Sørlie \& Myhre, 1977; Jorfeldt et al. 1978; Andersen \& Saltin, 1985), in which the latter authors optimized the technique for measurements of venous outflow from an isolated muscle group. As in vitro studies have shown that the saline may be slightly warmed during the passage through the external tubing and catheter (Gonzales et al. 1998), accuracy can be improved by measuring the temperature of the infusate. At rest bolus injections are often used. To calculate flow the mean temperature change is integrated over the time period of the effect. The infusion rate is determined from the volume injected over the time period of its effect. However, since the boluses only reflect a short period of time, and since blood flow is affected by many factors such as the cardiac cycle, blood pressure, breathing patterns, slight movements and 'vasalva' manoeuvres, a rigid control has to be undertaken to minimize the variability. Continuous infusion is also commonly used at rest, but care has to be taken to prevent cooling of the tissue. Moreover, since blood flow during exercise is markedly affected by the variations in intramuscular pressure, mathematical integration of the curve should be performed during as many contractionrelaxation cycles as possible, i.e. for approximately $10 \mathrm{~s}$. In order to eliminate the dependence on when the saline meets the blood, i.e. during a contraction or relaxation or both, continuous infusion is required rather than bolus injection. By continuously monitoring the blood and infusate temperature, attempts have also been made to perform rapid measurements. However, the theoretical basis for indicator techniques is that the measurements are performed during steady-state conditions.

Strength and weaknesses. Heat is the only indicator for which re-circulation can be fully ignored. Thus, with no recirculation problems this method allows for more frequent measurements than ICG infusion. Using continuous saline infusion, measurements can be performed at submaximal exercise intensities as well as at peak effort, independent of the exercise mode, as it is unaffected by movement artifacts. However, there has to be rigid control of the volume and frequency of saline infusion to avoid tissue cooling, haemodilution and too large a saline load. Moreover, with continuous infusion at rest, cooling of the surrounding tissue may be problematic. However, resting measurements are still of sufficient quality to be used as a baseline for comparison with exercise responses (Andersen \& Saltin, 1985). Although the technique is invasive, it is easy to use. Also, the equipment is inexpensive and running costs are low.

\section{Ultrasound Doppler}

Principle. The measurements are based on determining the Doppler frequency shift $(\Delta \mathrm{f})$ that occurs as transmitted sound waves of a specific frequency $f$ are reflected by the erythrocytes (Gill, 1979, 1985). The $\Delta \mathrm{f}$ contains information about both the magnitude and the direction of the flow. The direction is encoded such that $\Delta \mathrm{f}$ is positive or negative depending on whether the blood is moving towards or away from the direction of the transmitted sound waves, respectively. Information about the full parabolic velocity profile is obtained by sampling over the width of the artery. The velocity of blood (v) is calculated from the equation $\Delta \mathrm{f}=2 \times \mathrm{f} \times \mathrm{v} \times \cos \Theta / \mathrm{c}$, where $\Theta$ is the angle of insonation (direction of the transmitted sound wave beam towards the site of measurement) and $\mathrm{c}$ is the velocity of sound in tissue (approximately $1540 \mathrm{~m} / \mathrm{s}$ ). 
Practicalities. Ultrasound Doppler was introduced for medical purposes in the 1950s (Keidel, 1950; Wild \& Neal, 1951; Howry \& Bliss, 1952; Edler \& Hertz, 1954; Satamura \& Kaneko, 1960), but improvements were needed before estimates of blood flow could be performed during exercise (Wesche, 1986; Walløe \& Wesche, 1988). An ultrasound Doppler with a transducer possessing the capacity to both determine the arterial diameter and blood flow velocity is needed. Blood flow (litres $/ \mathrm{min})=6 \times 10^{4} \times \mathrm{v}_{\text {mean }} \times \mathrm{A}$, is thus calculated by multiplying the cross-sectional area of the artery (A) with the angle corrected, time and space averaged, and amplitude (signal intensity) weighted mean blood velocity $\left(\mathrm{v}_{\text {mean }} ; \mathrm{m} / \mathrm{s}\right)$. The constant $6 \times 10^{4}$ converts $\mathrm{m} / \mathrm{s}$ to litres/min.

Measurement of and correction for the insonation angle are important in obtaining accurate flow estimates. Insonation angles below $60^{\circ}$ are recommended for the velocity measurements, since the lower the insonation angle the less error may be induced in the flow estimate. Moreover, the pulsed-wave Doppler mode allows for measurement at the specific depths required, over the width of the vessel diameter and parabolic velocity profile. However, the arterial diameter measurements should be obtained under perpendicular insonation. Furthermore, the best image resolution is obtained in the axial direction of the transmitted sound beam. Since the diameter of the artery oscillates with each pulsation, a diameter $\left(\mathrm{D}_{\text {(systole/3)+(diastole } \times 2 / 3)}\right)$ based on the relative time periods of the systolic $(1 / 3)$ and diastolic $(2 / 3)$ blood pressure phases may be used to determine the cross-sectional area $\left(A=\pi r^{2}\right.$, where $r$ is the radius; $\left.2 r=D_{(\text {systole/3)+(diastole } \times 2 / 3)}\right)$; Rådegran, 1997). However, the fluctuation in the size of the arterial diameters is very small (Eriksen, 1992). The fluctuations between systole and diastole in the femoral artery are actually of the same magnitude as the spatial resolution (Rådegran, 1997), and are a minimal problem in relation to the accuracy of the flow measurements. The spatial resolution corresponds to half the spatial wavelength, i.e. approximately $0.1 \mathrm{~mm}$; spatial wavelength $=\mathrm{c} / \mathrm{f}$, where $\mathrm{c}$ is the velocity of sound in soft tissue $(1540 \mathrm{~m} / \mathrm{s})$ with an imaging frequency $\mathrm{f}$ of $7.5 \mathrm{MHz}$ (Chapman, 1990). Moreover, the larger the vessel, the lower the impact any diameter measurement error will have on the flow estimate (Gill, 1985). As the size of the femoral artery does not alter during dynamic knee-extensor exercise compared with rest (Rådegran, 1997), femoral artery blood flow during exercise can be based on the diameter at rest, eliminating measurement errors potentially introduced by frequently altering the insonation angle.

Strength and weaknesses. The ultrasound Doppler is unique as it allows continuous blood-flow measurements with a high temporal resolution. As the precision and accuracy of the technique have been improved by sampling the blood velocity continuously (Rådegran, 1997) instead of averaging the velocity in relation to each cardiac cycle (Wesche, 1986; Walløe \& Wesche, 1988), it is now possible to differentiate between physiological and methodological variations, as well as detect rapid changes in flow induced by exercise, different metabolic states, or any other type of vasodilatation. With a well-trained operator, the day-to-day variability is also minimal (Shoemaker et al. 1996). Thus, the ultrasound Doppler is currently the most sensitive technique for blood-flow measurement at rest, at onset of and during submaximal exercise, as well as post exercise. However, to avoid insonation failures, the exercise mode must be such that the limb and the artery are in a fixed position, as for instance during knee-extensor and specific types of forearm exercise. However, the technique is expensive, technically advanced and time-consuming to learn.

\section{Magnetic resonance velocity imaging}

Principle. Phase-contrast magnetic resonance velocity imaging, is based on the principle that the hydrogen nuclei in blood moving through a magnetic-field gradient accumulate a phase shift proportional to their velocity (Firmin et al. 1987; Hundley et al. 1996).

Practicalities. Blood flow is calculated by integrating the blood velocity over the cross-sectional area of the vessel (Hundley et al. 1996). Blood-flow $(\mathrm{ml} / \mathrm{min})=$ $\mathrm{V}_{\text {mean }} \times \mathrm{A} \times 60$, where $\mathrm{V}_{\text {mean }}(\mathrm{cm} / \mathrm{s})$ is the mean velocity and A $\left(\mathrm{cm}^{2}\right)$ is the cross-sectional area of the vessel (both determined using magnetic resonance imaging), and the factor 60 converts s/min to $\mathrm{ml} / \mathrm{min}$.

Strength and weaknesses. Magnetic resonance velocity imaging has recently evolved as an unique possibility for determining local blood flow in deep single vessels (Firmin et al. 1987; Enzmann et al. 1993; Zananiri et al. 1993; Li et al. 1995; McCauley et al. 1995; Hundley et al. 1996). The technique is non-invasive and does not require injection of any tracer molecule. An advantage over ultrasound Doppler is that the angle of insonation does not have to be determined (Zananiri et al. 1993). An advantage over PET is that no isotopes are needed (Vallé et al. 1998). The temporal and spatial resolution has also been suggested to be slightly better than that with PET (Vallé et al. 1998). Magnetic resonance imaging equipment is also more readily available than PET (Vallé et al. 1998). However, the equipment and running costs are very high. The apparatus and imaging procedures are also cumbersome, limiting the type and intensity of exercise that can be studied.

\section{Local blood flow measurements}

\section{Isotope clearance}

Principle. The method is based on the principle that the clearance of a molecule or ion is purely flow-dependent (Kety, 1951).

Practicalities. The tracer is administered by intramuscular injection. With external observation of its clearance rate depicted as a wash-out curve (Lassen et al. 1964), a measure of muscle perfusion or capillary flow is obtained. A fast wash-out rate results when exercise is started. Muscle blood flow is calculated from the slope of the wash-out curve. Blood-flow $(\mathrm{ml} / \mathrm{min}$ per $100 \mathrm{~g})=$ $100 \times \lambda_{\mathrm{m}} \times k_{m}$, where $\lambda_{\mathrm{m}}$ is the partition coefficient for muscle and $k_{m}$ is the rate-constant (Lassen et al. 1983).

Strength and weaknesses. The isotope-clearance technique has been utilized to measure blood flow during dynamic exercise (Tønnesen, 1964; Grimby et al. 1967; 
Bonde-Petersen et al. 1975). Different tracers have been used. As the lipid cell membranes impose no barrier to ${ }^{133} \mathrm{Xe}$, the tissue distribution of the tracer was improved by injecting the lipophilic ${ }^{133} \mathrm{Xe}$ instead of the hydrophilic ${ }^{24} \mathrm{Na}$ (Lassen et al. 1964). ${ }^{133} \mathrm{Xe}$ also maintains equilibrium between tissue and venous effluent better than ${ }^{24} \mathrm{Na}$ at high flow rates (Lassen et al. 1983), which is required by the wash-out technique. However, the method was found to be non-linear and to underestimate blood flow (Clausen \& Lassen, 1971; Bonde-Petersen et al. 1975; Cerretelli et al. 1984; Rowell, 1993). As indicated in previous reviews (Lassen et al. 1983; Rowell, 1993), this underestimation could be due to the fact that the measurements were affected by: different solubility constants of muscle, connective tissue and fat; exchange of isotopes between arterioles and veins; dissociation of labelled moieties with diffusion limiting clearance; injection trauma producing local hyperaemia (most pronounced at low flow rates); site of injection in the muscle. Thus, one reason for the levelling off in peak muscle blood flow may be the different solubility of tracers in various muscle components. The partition coefficient in skeletal muscle is $0.7 \mathrm{ml} / \mathrm{g}$, which is much lower than that in other tissues such as fat. The amount of adipose cells and connective tissue surrounding the vessels and separating the muscle cells may therefore reduce the wash-out rate and underestimate flow. Furthermore, correct values for blood flow at rest are hard to obtain due to shunting by diffusion and re-circulation (Tønnesen \& Sejrsen, 1970; Lassen et al. 1983). Calculation of blood flow from the constant shallow slope of the wash-out curve may also underestimate blood flow by approximately $50 \%$. Furthermore, because of an initial injection artifact there must be an interval of approximately $10 \mathrm{~min}$ before measurements are performed. The type of mathematical analysis utilized to compute blood flow may also influence the results. Thus, in addition to the requirement for injection of a radioactive molecule, there are many theoretical limitations. However, estimates of relative changes in blood flow may be of value (Tønnesen \& Sejrsen, 1970; Lassen et al. 1983), but the equipment is expensive and running costs are relatively high.

\section{Microdialysis ethanol outflow : inflow}

Principle. The technique is based on measurement of the transport of molecules across the semi-permeable membrane of a microdialysis fibre inserted into the muscle. By perfusing the fibre with an infusate containing ethanol (i.e. a tracer suggested to be metabolically inert in the muscle), and measuring the ethanol concentration in the outflowing dialysate, the loss of ethanol is suggested to be proportional to the local muscle blood flow surrounding the fibre (Hickner et al. 1991).

Practicalities. The microdialysis ethanol outflow: inflow value (ethanol dialysate $_{\text {: ethanol }}$ infusate $_{\text {) }}$ is therefore suggested to represent relative changes in local muscle blood flow (Hickner et al. 1991). As the dialysate concentration is dependent on the perfusion rate through the fibres, an accurate perfusion pump is needed. The microdialysis fibres are also very delicate and must be inserted carefully into the muscle. Some microdialysis fibres may also be damaged during exercise due to the contractions.
Also, the collected samples must be properly handled as ethanol easily evaporates.

The method has been used in attempts to estimate changes in local blood flow in skeletal muscle of animals and human subjects (Hickner et al. 1992, 1994a,b, 1995; Rosdahl et al. 1993; Wallgren et al. 1995). However, when the ethanol-removal technique was established it was specifically validated against ${ }^{133} \mathrm{Xe}$ clearance (Hickner et al. $1994 a$ ), which is known to be non-linear and to underestimate muscle blood flow. Furthermore, there was no investigation of whether the changes in ethanol removal during muscular contractions only represented changes in muscle blood flow, or whether it reflected other factors causing alterations in the molecular transport across the membrane. By determining the relative loss of labelled molecules across the membrane, it was recently found that arterial infusion of the vasodilator adenosine in the absence of muscle contractions did not change either the ethanol outflow: inflow value or the transport across the membrane (Rådegran et al. 1998). However, both factors were altered by muscle contractions (Rådegran et al. 1998). Thus, other factors may have a larger influence on the ethanol outflow: inflow than local blood flow.

Strength and weaknesses. In essence, microdialysis has evolved as an unique tool to measure local interstitial release of metabolites and vasodilators in relation to local blood flow. Although the technique is extensively used with pharmacological interventions, further studies are still needed to elucidate the different factors that may alter the transport across the membrane, as well as to define the direct sensitivity of the method in detecting changes in flow. Further investigation is also necessary to evaluate whether tracers other than ethanol may be used (Stallknecht et al. 1999). Moreover, although the equipment used is relatively inexpensive, the costs of the microdialysis probes for human use are high.

\section{Near i.r. spectroscopy}

Principle. In analogy with ICG regional blood flow measurements, where a photo-densitometer is used to detect the dye concentration, the NIRS-ICG method is based on detecting the light attenuation that is induced in the muscle during infusion of ICG (Boushel et al. 1997).

Practicalities. NIRS allows measurements to be made of concentration changes of oxyhaemoglobin, deoxyhaemoglobin and total haemoglobin in local muscle regions. Changes in these concentrations were previously used as a measure of local muscle blood flow (Edwards et al. 1993; De Blasi et al. 1994). However, as blood flow and delivery of $\mathrm{O}_{2}$ to the muscle may be independent of the $\mathrm{O}_{2}$ consumption the NIRS-ICG procedure is a better concept for estimating local blood flow. Muscle perfusion is determined using a combination of NIRS, venous infusion of ICG and arterial concentration measurements of ICG (Boushel et al. 1997). Following the venous infusion of ICG, the tracer is rapidly bound to plasma proteins, with albumin as the predominant carrier. The quantified values of the rapid component of ICG accumulation in the muscle are thus taken to represent capillary blood flow. This value is based on the fact that the early component is thought to 
represent the period before blood containing ICG has reached the venous side, whereby only the arterial concentration is required as an input function for the calculation. The light-emitting and -receiving optodes are placed several $\mathrm{mm}$ apart. With an algorithm (Hamamatsu Photonics K.K., Hamamatsu, Japan) using the extinction coefficients for ICG at $775,826,859$, and $910 \mathrm{~nm}$, the change in ICG concentration is determined. Muscle blood flow $(\mathrm{ml} / \mathrm{min}$ per $100 \mathrm{~g}$ ) is then calculated according to the formula, blood flow $=k \times\left(\mathrm{ICG}_{\mathrm{mu}}\right)(\mathrm{t}) / \mathrm{O} \int^{\mathrm{t}}\left(\mathrm{ICG}_{\mathrm{a}}\right) \mathrm{dt}$, where $\mathrm{ICG}_{\mathrm{a}}(\mathrm{mg} / \mathrm{l})$ is the integrated arterial ICG concentration and $\mathrm{ICG}_{\mathrm{mu}}$ is the ICG accumulated in the muscle. The constant $k$ includes the density of the muscle $(1.04 \mathrm{~g} / \mathrm{ml})$ and the molecular mass of ICG.

Strength and weaknesses. The technique is unique, as it allows an estimate to be made of local muscle oxygenation in relation to local perfusion. However, further methodological work is needed to verify how the NIRS-ICG blood flow measurements correspond to regional arterial inflow and venous outflow. Although the NIRS technique is noninvasive, the method requires invasive ICG infusion and arterial blood sampling. Also, the equipment and ICG are relatively expensive.

\section{Positron emission tomography}

Principle. PET is based on imaging of biochemical processes in vivo after infusion of 'natural' substrates labelled with short-lived positron-emitting isotopes, and detection of $\gamma$ rays resulting from the interactions between positrons and electrons (Raitakari, 1996).

Practicalities. Tracers such as ${ }^{82} \mathrm{Rb},{ }^{13} \mathrm{NH}_{3}$, and $\mathrm{H}_{2}{ }^{15} \mathrm{O}$ have been used for blood flow measurements (Herscovitch et al. 1983; Raichle et al. 1983; Choi et al. 1993; Muzik et al. 1993; Raitakari, 1996; Raitakari et al. 1996). However, the ideal tracer for measurement of blood flow should be freely diffusable and inert with respect to changes in tissue metabolism (Raitakari, 1996), which is the case for $\mathrm{H}_{2}{ }^{15} \mathrm{O}$. Furthermore, its half-life of approximately $2 \mathrm{~min}$ allows repetitive measurements. $\mathrm{Rb}$, which is a $\mathrm{K}^{+}$analogue, is not ideal as it may be affected by substances that influence the membrane transport of $\mathrm{K}^{+} .{ }^{13} \mathrm{NH}_{3}$ is not appropriate in skeletal muscle because it may be dependent on the tissue metabolism.

The muscle blood flow (ml/min per $100 \mathrm{~g}$ ) may be modelled according to the autoradiographic or the steadystate method (Raitakari, 1996). The autoradiographic method allows numerical calculation of flow according to the equation: $\int_{0}^{T \mathrm{~T}} \mathrm{C}(\mathrm{t}) \mathrm{dt}={ }_{0} \int^{\mathrm{T}} \mathrm{BF}_{\mathrm{PET}} \times \mathrm{C}_{\mathrm{a}}(\mathrm{t}) *$ $\exp \left(-\mathrm{BF}_{\mathrm{PET}} \times \mathrm{t} / p\right) \mathrm{dt}$, where $\mathrm{BF}_{\mathrm{PET}}$ is the blood flow. The righthand side of the equation is calculated from the decaycorrected arterial time $v$. radioactivity curve $\mathrm{C}_{\mathrm{a}}(\mathrm{t})$ for different flow levels, assuming a constant value for the partition coefficient $(p)$, and $*$ denotes the convolution integral (Raitakari, 1996). The lefthand side corresponds to the pixel-by-pixel solved integral of the decay-corrected tissue time $v$. radioactivity curve. $\mathrm{T}$ corresponds to the integration time. The steady-state method is based on continuous administration of $\mathrm{H}_{2}{ }^{15} \mathrm{O}$, where the tissue radioactivity concentration reaches an equilibrium when the constant administration of radioactivity is in balance with the wash-out and tracer decay. Blood flow is calculated as $\lambda /\left(\left(\mathrm{C}_{\mathrm{a}-\text { avg }} / \mathrm{C}_{\mathrm{t} \text {-avg }}\right)-(1 / p)\right)$, where $\lambda$ denotes the decay constant of ${ }^{15} \mathrm{O}, p$ is the partition coefficient of water in muscle tissue, and $\mathrm{C}_{\mathrm{a} \text {-avg }}$ and $\mathrm{C}_{\mathrm{t} \text {-avg }}$ are the average radioactivity concentrations in blood and tissue respectively, during steady-state condition.

Strength and weaknesses. PET allows direct quantification of muscle blood flow without contamination from other tissue compartments. Furthermore, it is unique in allowing spatial and temporal quantification of the distribution of a label. The link between local metabolic activity and blood flow, as well as local blood flow distribution, may therefore be studied. However, PET requires injection of positron-emitting isotopes. The equipment is expensive and running costs are also extremely high. The potential for many researchers to use the technique is therefore limited. Moreover, the apparatus, imaging, and data retrieval procedure restrict the type of exercise mode that can be studied.

\section{Laser Doppler}

Principle. Laser Doppler is based on the same principle as ultrasound Doppler, but instead of ultrasonic waves, divergent (non-collimated) continuous-wave (non-pulsed) monochromatic light is used.

Practicalities. The laser light is applied via an optic fibre inserted through the subcutaneous tissue into the muscle. The fibre allows bi-directional travel of light, and thereby detection of the Doppler shift in the light scattered by the moving erythrocytes. The magnitude and frequency distribution of this Doppler shift is a collective property related to both the number and velocity of the erythrocytes. The Doppler shift is used as a relative estimate of changes in flow, expressed in arbitrary flux units. Fig. 4 shows the blood flow response to a bolus injection of adenosine.

Strength and weaknesses. Traditionally, laser Doppler has been used to estimate changes in skin blood flow (Holloway \& Watkins, 1977). However, the technique could have potential for use in the study of relative changes in local muscle blood flow induced by pharmacological interventions. The sensitivity of the technique, with respect to the minimal vasodilatation and vasoconstriction that can be registered, still remains to be investigated. Whereas laser Doppler has already been used to estimate changes in human muscle blood flow during isometric contractions (Jensen et al. 1995), the technique needs to be evaluated during dynamic contractions. It is likely, however, that movement artifacts during exercise may be problematic. Furthermore, an absolute quantitative measure of blood flow will not be possible, as there are no means of estimating the vessel diameters from which the laser Doppler signal originate. The equipment is relatively expensive, but the running costs are low.

\section{Discussion}

Accurate measurements of blood flow are of particular importance both at rest and during exercise, since blood flow is used to estimate the substrate fluxes, energy turnover and metabolic rate of skeletal muscle. As long as the period 

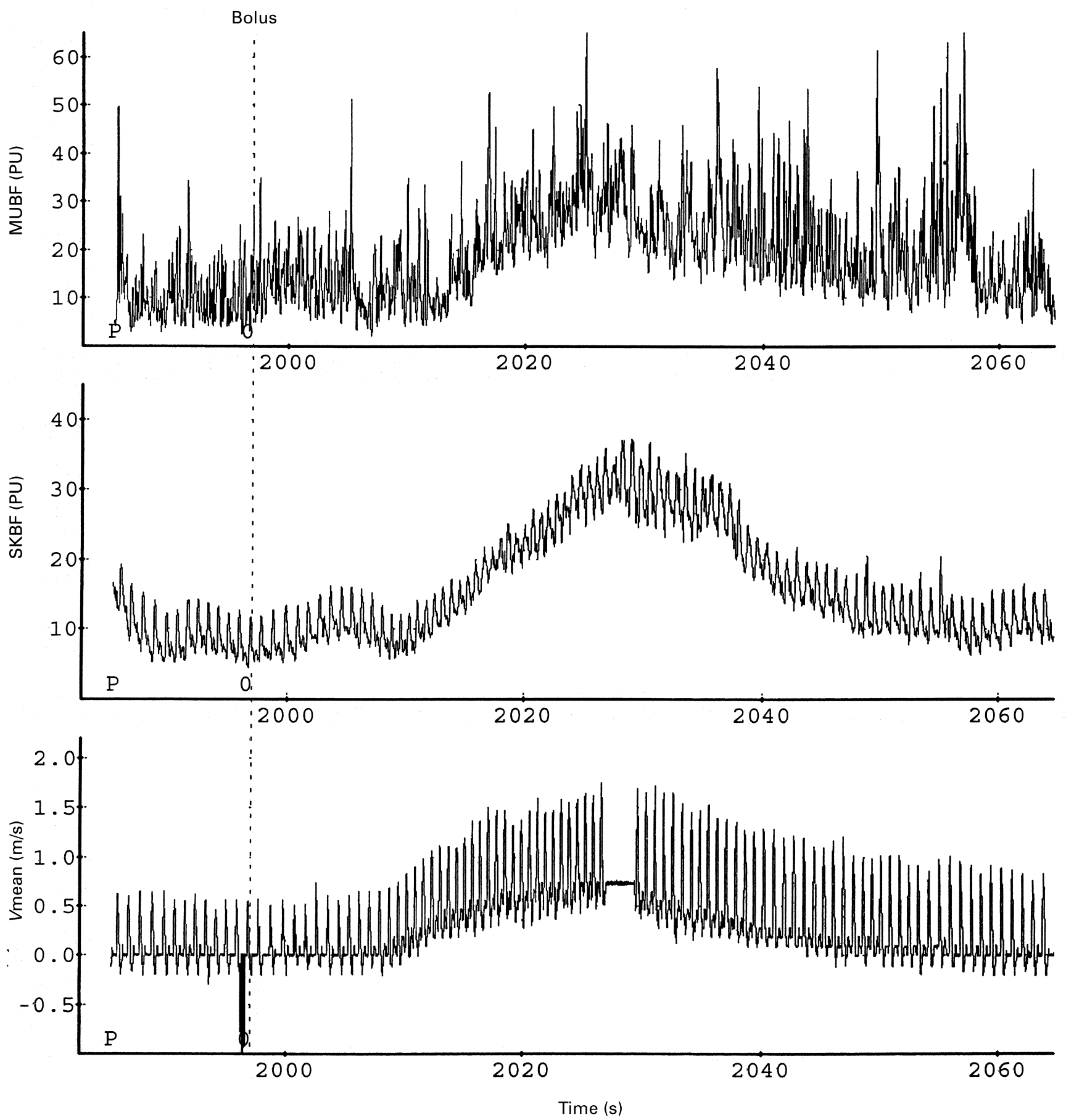

Fig. 4. Femoral artery blood velocity (Vmean, representing arterial inflow; ultrasound Doppler), skin blood flow (SKBF; laser Doppler), and muscle blood flow (MUBF; laser Doppler) during a bolus injection $(2.5 \mathrm{mg})$ of adenosine into the femoral artery of a representative human subject at rest (i). Femoral artery blood flow, SKBF and MUBF transiently increased by a peak factor of approximately $11.5,3.5$ and 2.9 respectively. PU are arbitrary perfusion units, as measured using a PeriFlux 4001 laser Doppler (Perimed, Järfälla, Sweden) operating at a maximal emission of $780 \mathrm{~nm}$.

of the blood-flow oscillations is short in relation to the time period of metabolic measurements, the mean value for blood flow is acceptable for the theoretical assumptions of steadystate. As skeletal muscle blood flow dramatically increases from rest to exercise, and since the flow markedly fluctuates with the intramuscular pressure variations during exercise, with the cardiac cycle and arterial blood pressure as a super- imposed modulator, the method used must not only be sensitive, but also allow for measurement during both contraction and relaxation phases. In addition, as blood flow in recovery post exercise decreases as the metabolic influence ceases, and since blood flow during exercise is not only affected by metabolic vasodilatation but also by the effects of muscle mechanical factors, post-exercise 
measurements are not representative of exercise. Moreover, measurements of arterial inflow to or venous outflow from a limb have generally been taken to reflect muscle blood flow. This assumption is reasonable when comparing changes in blood flow from rest to during muscle contraction. In order to minimize the contribution of non-active tissue compartments, exercise modes such as the knee-extensor model have been developed where the circulation to the lower leg is excluded by a cuff around the calf (Andersen \& Saltin, 1985).

In addition to the technical limitations of each method, the focus of each metabolic study and the type of interventions performed determine which technique may be suitable. The electromagnetic flow meters are too invasive for use in healthy human subjects. Moreover, due to occlusion and motion artifacts, plethysmography is not suitable for measurements during exercise, but is limited to intermittent measurements at rest. The isotope-clearance method also has limited application for accurate measurements of skeletal muscle blood flow during exercise. The two best techniques for measurements at rest are ultrasound Doppler and continuous ICG dye infusion. In addition to the advantage of being non-invasive, ultrasound Doppler also has a better temporal resolution, which allows detection of normal physiological variations. Thus, transitional states, such as onset of and recovery from exercise, are also characterized best by continuous ultrasound Doppler measurements. However, the exercise mode must be such that the artery is in a fixed position. Ultrasound Doppler, thermodilution and ICG dye dilution are comparable options during steady-state submaximal exercise. However, thermodilution and ICG dye dilution are preferable at peak effort and during exercise with marked limb movements. Furthermore, thermodilution is slightly easier to use than ICG dye dilution, and is not affected by recirculation.

Thus, currently, ultrasound Doppler, thermodilution and ICG dye infusion seem to be the three best complementing techniques for regional blood-flow measurements in human subjects during various modes of exercise. Magnetic resonance velocity imaging offers the unique possibility of determining the blood flow in deep single vessels. For local blood-flow measurements in relation to metabolic activity, PET seems to be the most promising tool for the future.

\section{Acknowledgements}

The present work was supported by a grant from the Danish National Research Foundation (504-14).

\section{References}

Andersen P \& Saltin B (1985) Maximal perfusion of skeletal muscle in man. Journal of Physiology 366, 233-249.

Barcroft H \& Dornhorst AC (1949) The blood flow through the human calf during rhythmic exercise. Journal of Physiology 109, 402-411.

Benjamin N, Calver A, Collier J, Robinson B, Vallance P \& Webb D (1995) Measuring forearm blood flow and interpreting the responses to drugs and mediators. Hypertension 25, 918-923.

Bonde-Petersen F, Henriksson J \& Lundin B (1975) Blood flow in thigh muscle during bicycling exercise at varying work rates. European Journal of Applied Physiology 34, 191-197.
Bonde-Petersen F \& Siggaard-Andersen J (1967) Blood flow in skin and muscle, evaluated by simultaneous venous occlusion plethysmography and ${ }^{133} \mathrm{Xe}$ clearance. Scandinavian Journal of Clinical and Laboratory Investigation 19, 113-119.

Bonde-Petersen F \& Siggaard-Andersen J (1969) Simultaneous venous occlusion plethysmography and ${ }^{133} \mathrm{Xe}$ clearance in patients with arteriosclerosis of the lower extremities. An attempt to evaluate the blood flow in skin and muscle. Scandinavian Journal of Thoracic Cardiovascular Surgery 3, 20-25.

Boushel R, Ide K, Møller-Sørensen H, Fernandes A, Pott F \& Secher N (1997) Muscle microvascular blood flow during exercise determined by near infrared spectroscopy. Journal of Biomedical Optics 1, 145-149.

Brodie TG \& Russell AE (1905) On the determination of the rate of blood-flow through an organ. Journal of Physiology 32, 47-49.

Bygdeman S \& Pernow B (1978) Venös ocklutionspletysmografi (Venous occlusion plethysmography). In Perifer Cirkulation. Kliniska Fysiologiska Undersökningsmetoder (Peripheral Circulation. Clinical Physiological Investigation Methods), pp. 61-74 [B Pernow, editor]. Stockholm: AWE Gebers.

Byström S, Jensen B, Jensen-Urstad M, Lindblad LE \& Kilbom A (1998) Ultrasound-Doppler technique for monitoring blood flow in the brachial artery compared with occlusion plethysmography of the forearm. Scandinavian Journal of Clinical and Laboratory Investigation 58, 569-576.

Cerretelli P, Marconi C, Pendergast D, Meyer M, Heisler N \& Piiper J (1984) Blood flow in exercising muscles by xenon clearance and by microsphere trapping. Journal of Applied Physiology 56, 24-30.

Chapman JV (1990) The technical aspects of Doppler ultrasound. In The Noninvasive Evaluation of Hemodynamics in Congenital Heart Disease, pp. 1-34 [JV Chapman and GR Sutherland, editors]. London: Kluwer Academic Publisher.

Choi Y, Huang SC, Hawkins RA, Kuhle WG, Dahlbom M, Hoh CK, Czernin J, Phelps ME \& Schelbert HR (1993) A simplified method for quantification of myocardial blood flow using nitrogen-13-ammonia and dynamic PET. Journal of Nuclear Medicine 34, 488-497.

Clausen JP \& Lassen NA (1971) Muscle blood flow during exercise in normal man studied by the 133 -xenon clearance method. Cardiovascular Research 5, 245-254.

Conrad MC \& Green HD (1961) Evaluation of venous occlusion plethysmography. Journal of Applied Physiology 16, 289-292.

Cronestrand R (1970) Leg blood flow at rest and during exercise after reconstruction for occlusive disease. Scandinavian Journal of Thoracic Cardiovascular Surgery, Suppl. 4, 1-24.

De Blasi RA, Ferrari M, Natali A, Conti G, Mega A \& Gasparetto A (1994) Noninvasive measurement of forearm blood flow and oxygen consumption by near-infrared spectroscopy. Journal of Applied Physiology 76, 1388-1393.

Djordjevich L \& Sadove MS (1981) Basic principles of electrohaemodynamics. Journal of Biomedical Engineering 3, 25-33.

Edler I \& Hertz CH (1954) Use of ultrasonic reflectoscope for continuous recording of movements of heart wall. Kungliga Fysiografiska Sällskapet 24, 40-58.

Edwards AD, Richardson C, van der Zee P, Elwell C, Wyatt JS, Cope M, Delpy DT \& Reynolds EOR (1993) Measurement of hemoglobin flow and blood flow by near infrared spectroscopy. Journal of Applied Physiology 75, 1884-1889.

Enzmann DR, Marks MP \& Pelc NJ (1993) Comparison of cerebral artery blood flow measurements with gated cine and ungated phase-contrast techniques. Journal of Magnetic Resonance Imaging 3, 705-712.

Eriksen M (1992) Effects of pulsatile arterial diameter variations on blood flow estimated by Doppler Ultrasound. Medical and Biological Engineering and Computation 30, 46-50. 
Fegler G (1954) Measurement of cardiac output in anaesthethized animals by a thermo-dilution method. Quarterly Journal of Experimental Physiology 39, 153-164.

Firmin DN, Nayler GL, Klipstein RH, Underwood SR, Rees RSO \& Longmore DB (1987) In vivo validation of MR velocity imaging. Journal of Computer Assisted Tomography 11, 751-756.

Fronek A \& Ganz V (1960) Measurement of flow in single blood vessels including cardiac output by local thermodilution. Circulation Research 8, 175-182.

Ganz V, Hlavová A, Fronek A, Linhart J \& Prerovsky I (1964) Measurement of blood flow in the femoral artery in man at rest and during exercise by local thermodilution. Circulation 30, 86-89.

Ganz W \& Swan HJC (1974) Measurement of blood flow by the thermodilution technique. In The Theory and Practice of Indicator Dilution, pp. 245-266 [DA Bloomfield, editor]. Baltimore, MD: University Park Press.

Gill RW (1979) Pulsed doppler with b-mode imaging for quantitative blood flow measurement. Ultrasound in Medicine and Biology 5, 223-235.

Gill RW (1985) Measurement of blood flow by ultrasound: accuracy and sources of error. Ultrasound in Medicine and Biology 11, 625-641.

Gonzales JA, Calbet JAL \& Nielsen B (1998) Muscle blood flow is reduced with dehydration during prolonged exercise in humans. Journal of Physiology 513, 895-905.

Grimby G, Häggendahl E \& Saltin B (1967) Local ${ }^{133}$ xenon clearance from the quadriceps muscle during exercise in man. Journal of Applied Physiology 22, 305-310.

Hall KV (1969) Postoperative blood flow measurements in man by the use of implanted electromagnetic probes. Scandinavian Journal of Thoracic Cardiovascular Surgery 3, 135-144.

Herscovitch P, Markham J \& Raichle ME (1983) Brain blood flow measured with intravenous $\mathrm{H}_{2}{ }^{15} \mathrm{O}$. I. Theory and error analysis. Journal of Nuclear Medicine 24, 782-789.

Hewlett AW \& van Zwaluwenburg JG (1909) The rate of blood flow in the arm. Heart 1, 87-97.

Hickner RC, Bone D, Ungerstedt U, Jorfeldt L \& Henriksson J (1994a) Muscle blood flow during intermittent exercise: comparison of the microdialysis ethanol technique and ${ }^{133} \mathrm{Xe}$ clearance. Clinical Science 86, 15-25.

Hickner RC, Ekelund U, Mellander S, Ungerstedt U \& Henriksson J (1995) Muscle blood flow in cats: comparison of microdialysis ethanol technique with direct measurement. Journal of Applied Physiology 79, 638-647.

Hickner RC, Rosdahl H, Borg I, Ungerstedt U, Jorfeldt L \& Henriksson J (1991) Ethanol may be used with the microdialysis technique to monitor blood flow changes in skeletal muscle: dialysate glucose concentration is blood-flow-dependent. Acta Physiologica Scandinavica 143, 355-356.

Hickner RC, Rosdahl H, Borg I, Ungerstedt U, Jorfeldt L \& Henriksson J (1992) The ethanol technique of monitoring local blood flow changes in rat skeletal muscle: implications for microdialysis. Acta Physiologica Scandinavica 146, 87-97.

Hickner RC, Ungerstedt U \& Henriksson J (1994b) Regulation of skeletal muscle blood flow during acute insulin-induced hypoglycemia in the rat. Diabetes 43, 1340-1344.

Holloway GA \& Watkins DW (1977) Laser Doppler measurements of cutaneous blood flow. Journal of Investigative Dermatology 69, 306-309.

Howry DH \& Bliss WR (1952) Ultrasonic visualization of soft tissue structures in the body. Journal of Laboratory and Clinical Medicine 40, 579-592.

Hundley WG, Lange RA, Clarke GD, Meshack BM, Payne J, Landau C, McColl R, Sayad DE, Willet DW, Willard JE, Hillis LD \& Peshock RM (1996) Assessment of coronary flow and flow reserve in humans with magnetic resonance imaging. Circulation 93, 1502-1508.

Jensen BR, Sjøgaard G, Bornmyr S, Arborelius M \& Jørgensen K (1995) Intramuscular laser-Doppler flowmetry in the supraspinatus muscle during isometric contractions. European Journal of Applied Physiology 71, 373-378.

Jorfeldt L, Juhlin-Dannfelt A, Pernow B \& Wassén E (1978) Determination of human leg blood flow: a thermodilution technique based on femoral venous bolus injection. Clinical Science and Molecular Medicine 54, 517-523.

Jorfeldt L \& Wahren J (1971) Leg blood flow during exercise in man. Clinical Science 41, 459-473.

Keidel WD (1950) Über eine methode zur repiestrierig der volumanderung des herzens am menschen (A new method for recording volume changes of the heart in man). Zeitschrift für Kreislaufforschung 39, 257-271.

Kety S (1951) The theory and applications of the exchange of inert gas at the lung and tissues. Pharmacology Review 3, 1-41.

Kolin A (1936) An electromagnetic flowmeter. Principle of the method and its application to blood flow measurements. Proceedings of the Society for Experimental of Biology and Medicine 35, 53-56.

Kolin A (1941) An A.C. induction flow meter for measurement of blood flow in intact blood vessels. Proceedings of the Society for Experimental Biology and Medicine 46, 235-239.

Lassen NA, Henriksen O \& Sejrsen P (1983) Indicator methods for measurement of organ and tissue blood flow. In Handbook of Physiology. Section 2, The Cardiovascular System: Peripheral Circulation and Organ Blood Flow, vol. 3, part 1, pp. 21-63 [JT Shepherd, FM Abboud and SR Geiger, editors]. Bethesda, MD: American Physiology Society.

Lassen NA, Linbjerg I \& Munck O (1964) Measurement of blood flow through skeletal muscle by intramuscular injection of xenon 133. Lancet i, 686-689.

Li H, Clarke GD, NessAvier M, Liu H \& Peshock R (1995) Magnetic resonance imaging k-space segmentation using phaseencoding groups: The accuracy of quantitative measurements of pulsatile flow. Medical Physics 22, 391-399.

McCauley TR, Pena CS, Holland CK, Price TB \& Gore JC (1995) Validation of volume flow measurements with cine phasecontrast MR imaging for peripheral arterial waveforms. Journal of Magnetic Resonance Imaging 5, 663-668.

Muzik O, Beanlands RSB, Hutchins GD, Mangner TJ, Nguyen N \& Schwaiger M (1993) Validation of nitrogen-13-ammonia tracer kinetic model for quantification of myocardial blood flow using PET. Journal of Nuclear Medicine 34, 83-91.

Rådegran G (1997) Ultrasound Doppler estimates of femoral artery blood flow during dynamic knee extensor exercise in humans. Journal of Applied Physiology 83, 1383-1388.

Rådegran G, Pilegaard H, Nielsen JJ \& Bangsbo J (1998) Microdialysis ethanol removal reflects probe recovery rather than local blood flow in skeletal muscle. Journal of Applied Physiology 85, 751-757.

Rådegran G \& Saltin B (1998) Muscle blood flow at onset of dynamic exercise in humans. American Journal of Physiology 274, H314-H322.

Rådegran G \& Saltin B (1999) Nitric oxide in the regulation of vasomotor tone in human skeletal muscle. American Journal of Physiology 276, H1951-H1960.

Raichle ME, Martin WRW, Herscovitch P, Mintun MA \& Markham J (1983) Brain blood flow measured with intravenous $\mathrm{H}_{2}{ }^{15} \mathrm{O}$. II. Implementation and validation. Journal of Nuclear Medicine 24, 790-798.

Raitakari M (1996) Muscle blood flow and insulin sensitivity. Doctoral Thesis, Turku PET Center and the Department of Medicine and Nuclear Medicine, Turku, Finland. 
Raitakari M, Nuutila P, Ruotsalainen U, Teräs M, Eronen E, Laine H, Raitakari OT, Iida H, Knuuti MJ \& Yki-Järvinen H (1996) Relationship between limb and muscle blood flow in man. Journal of Physiology 496, 543-549.

Rosdahl H, Ungerstedt U, Jorfeldt L \& Henriksson J (1993) Interstitial glucose and lactate balance in human skeletal muscle and adipose tissue studied by microdialysis. Journal of Physiology 471, 637-657.

Rowell LB (1993) Human Cardiovascular Control. Oxford: Oxford University Press.

Ruotsalainen U, Raitakari M, Nuutila P, Oikonen V, Sipilä H, Teräs M, Knuuti J, Bloomfield PM \& Iida H (1997) Quantitative blood flow measurement of skeletal muscle using oxygen-15-water and PET. Journal of Nuclear Medicine 38, 314-319.

Saltin B (1985) Hemodynamic adaptions to exercise. American Journal of Cardiology 55, 42D-47D.

Saltin B \& Gollnick PD (1983) Skeletal muscle adaptability: significance for metabolism and performance. In Handbook of Physiology. Skeletal Muscle, pp. 555-631 [LD Peachey, RH Adrian and SR Geiger, editors]. Bethesda, MD: American Physiology Society.

Saltin B \& Rowell LB (1980) Functional adaptions to physical activity and inactivity. Federation Proceedings 39, 1506-1513.

Satamura S \& Kaneko Z (1960) Ultrasonic rheograph. Proceedings from the International Conference on Medical Electronics 3, 239-242.

Schäfer EA \& Moore B (1896) On the contractility and inervation of the spleen. Journal of Physiology 20, 1-51.

Shoemaker JK, Pozeg ZI \& Hughson RL (1996) Forearm blood flow by Doppler ultrasound during rest and exercise: test of day-to-day repeatability. Medicine and Science in Sports and Exercise 28, 1144-1149.

Siggaard-Andersen J (1970) Venous occlusion plethysmograph on the calf. Doctoral Thesis. University of Copenhagen, Denmark.

Siggaard-Andersen J \& Bonde-Petersen F (1967) Venous occlusion plethsmography and ${ }^{133} \mathrm{Xe}$ muscle clearance measured simultaneously on the calf in normal subjects. Scandinavian Journal of Clinical and Laboratory Investigation 19, 106-112.

Sørlie D \& Myhre K (1977) Determination of lower leg blood flow in man by thermodilution. Scandinavian Journal of Clinical and Laboratory Investigation 37, 117-124.

Stallknecht B, Donsmark M, Enevoldsen LH, Fluckey JD \& Galbo $\mathrm{H}$ (1999) Estimation of rat muscle blood flow by microdialysis probes perfused with ethanol, $\left[{ }^{14} \mathrm{C}\right]$ ethanol, and ${ }^{3} \mathrm{H}_{2} \mathrm{O}$. Journal of Applied Physiology 86, 1054-1061.

Stewart GN (1897) Researches on the circulation time and on the influences which affect it. IV. The output of the heart. Journal of Physiology 22, 159-183.
Stewart GN (1921) The pulmonary circulation time, the quantity of blood in the lungs and the output of the heart. American Journal of Physiology 58, 20-44.

Tønnesen KH (1964) Blood flow through muscle during rhythmic contraction measured by xenon. Scandinavian Journal of Clinical and Laboratory Investigation 16, 646-654.

Tønnesen KH \& Sejrsen P (1970) Washout of ${ }^{133}$ Xenon after intramuscular injection and direct measurement of blood flow in skeletal muscle. Scandinavian Journal of Clinical and Laboratory Investigation 25, 71-81.

Vallé JPM, Sostman HD, MacFall JR, DeGrado TR, Zhang J, Sebbag L, Cobb FR, Wheeler T, Hedlund LW, Turkington TG, Spritzer CE \& Coleman RE (1998) Quantification of myocardial perfusion by MRI after coronary occlusion. Magnetic Resonance in Medicine 40, 287-297.

Vänttinen E (1975) Electromagnetic measurement of the arterial blood flow in the femeropopliteal region. Acta Chirurgica Scandinavica 141, 353-359.

Wahren J \& Jorfeldt L (1973) Determination of leg blood flow during exercise in man: an indicator-dilution technique based on femoral venous dye infusion. Clinical Science and Molecular Medicine 45, 135-146.

Wallgren F, Amberg G, Hickner RC, Ekelund U, Jorfeldt L \& Henriksson J (1995) A mathematical model for measuring blood flow in skeletal muscle with the microdialysis ethanol technique. Journal of Applied Physiology 79, 648-659.

Walløe L \& Wesche J (1988) Time course and magnitude of blood flow changes in the human quadriceps muscles during and following rhythmic exercise. Journal of Physiology 405, 257-273.

Webster JG (1978) Medical Instrumentation - Application and Design. Boston, MA: Houghton Mifflin Company.

Wesche J (1986) The time course and magnitude of blood flow changes in the human quadriceps muscles following isometric contraction. Journal of Physiology 377, 445-462.

Whitney RJ (1953) The measurement of volume changes in human limbs. Journal of Physiology 121, 1-27.

Wild JJ \& Neal D (1951) Use of high frequency ultrasonic waves for detecting changes in texture in living tissues. Lancet $\mathbf{i}, 655$.

Williams CA \& Lind AR (1979) Measurement of forearm blood flow by venous occlusion plethysmography: influence of hand blood flow during sustained and intermittent isometric exercise. European Journal of Applied Physiology 42, 141-149.

Zananiri FV, Jackson PC, Halliwell M, Harris RA, Hayward JK, Davies ER \& Wells PNT (1993) A comparative study of velocity measurements in major blood vessels using magnetic resonance imaging and Doppler ultrasound. British Journal of Radiology 66, 1128-1133. 